\title{
Correction: Why Do You Believe in God? Relationships between Religious Belief, Analytic Thinking, Mentalizing and Moral Concern
}

\author{
Anthony lan Jack, Jared Parker Friedman, Richard Eleftherios Boyatzis, Scott \\ Nolan Taylor
}

There was an error in the coding of male and female participants in two studies, and the involvement of these data points in the pooled analysis.

In the Results and Discussion, Study 5 and Study 8 contain the incorrect signs for effects reported on gender.

Additionally, in the "Pooled Analysis" section of the Results and Discussion, there are some changes to the statistics reported in the regression analysis, of the order of $<1 \%$ in the values.

These differences do not affect the significance of any reported findings or any of the conclusions drawn in the manuscript.

The correlation coefficients remain unchanged, as we clarified in the caption to the tables that $1=$ Females and $2=$ Males.

\section{Supporting Information}

S1 File.

(DOCX)

\section{Reference}

1. Jack Al, Friedman JP, Boyatzis RE, Taylor SN (2016) Why Do You Believe in God? Relationships between Religious Belief, Analytic Thinking, Mentalizing and Moral Concern. PLoS ONE 11(3): e0149989. doi:10.1371/journal.pone.0149989 PMID: 27008093

\section{OPEN ACCESS}

Citation: Jack Al, Friedman JP, Boyatzis RE, Taylor SN (2016) Correction: Why Do You Believe in God? Relationships between Religious Belief, Analytic Thinking, Mentalizing and Moral Concern. PLoS ONE 11(5): e0155283. doi:10.1371/journal.pone.0155283

Published: May 11, 2016

Copyright: @ 2016 Jack et al. This is an open access article distributed under the terms of the Creative Commons Attribution License, which permits unrestricted use, distribution, and reproduction in any medium, provided the original author and source are credited. 